\title{
Compression bearing capacity analysis of concrete in edge and corner under prestressed constraint
}

\author{
Zhanshuo Cao ${ }^{1, a^{*}}$,Xinsheng Yin ${ }^{2, b}$,Jingwei Cai ${ }^{3, c}$ \\ ${ }^{1}$ Green Building Engineering Research Center fort Cold Area,Jilin Jianzhu University, Changchun, \\ Jilin, 130118,China

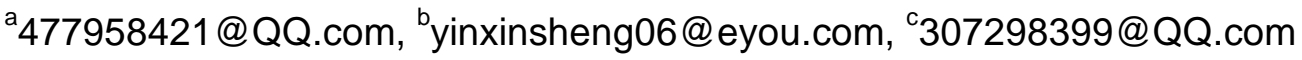

Keywords: local compression; prestress; steel net; bearing capacity;

Abstract. With the development of architectural diversity, local pressure has become a common form in civil engineering, the problem of compression bearing analysis of concrete in edge and corner become more and more prominent, under the prestressed constraints, the article try to study on the change of the pressure bearing capacity of the side angle by ABAQUS finite element software and analysis of the mechanism of bearing capacity. For this situation, the article can apply to conduct the capacity calculation and analysis, looking at the differences among the model of plain concrete with configuration of conventional steel net and plain concrete. Analysis of the model indicated that: Reasonably using prestressed steel net can improve the ultimate bearing capacity of the concrete members. With the increase of local compression area, the ultimate bearing capacity also increased significantly ${ }^{[1]}$. It has a certain meaning of the further research on the partial compression of concrete.

\section{Introduction}

In recent years, the concrete structure frequently have emerged local pressure in the field of engineering. For example: concrete strength grade of understructure less than post and wall of the top surface of foundation and so on. And then by improving concrete strength grade and configuring indirect steel bar of grid type or screw type to reduce local compression damage. Local pressure of concrete in edge and corner are the worst situation ${ }^{[2]}$. Today with the rapid development of prestress, steel bar of prestress have advantages in the field of civil engineering. prestressed concrete improve rigidity of structure and cracking resistance than general concrete. the article analysis concrete partial pressure working mechanism with steel bar of prestress by ABAQUS finite element software, research and calculate ultimate bearing capacity, also obtain the result of damage modes and cloud graphics for stress and strain. There is a conclusion that it's can increase bearing capacity of local compression component clearly also save the rolled steel.

\section{Set up model}

Local compression, It refers to the force state to the part of the area subjected to pressure. To achieve this state, the article simulate by ABAQUS finite element software, dividing three local compress forms, they are edge local compression $\left(100 \times 500 \mathrm{~mm}^{2}\right)$ 、 corner local compression $\left(100 \times 100 \mathrm{~mm}^{2}\right)$, corner local compression $\left(200 \times 200 \mathrm{~mm}^{2}\right)$. Detailed data as follows:

\begin{tabular}{|c|c|c|c|c|}
\hline & $\begin{array}{c}\text { Elastic Modulus } \\
{\left[\mathrm{N} / \mathrm{m}^{2}\right]}\end{array}$ & $\begin{array}{c}\text { Poisson's } \\
\text { ratio }\end{array}$ & $\begin{array}{c}\text { yield strength } \\
{[\mathrm{Mpa}]}\end{array}$ & $\begin{array}{c}\text { coefficient of linear } \\
\text { expansion }\end{array}$ \\
\hline concrete & $3.25 \mathrm{e} 10$ & 0.2 & 335 & $1.2 \mathrm{e}-5$ \\
\hline Steel mesh pieces & $2 \mathrm{e} 11$ & 0.3 & 1860 & \\
\hline $\begin{array}{c}\text { Prestressed } \\
\text { reinforcement fabric } \\
\text { piece }\end{array}$ & $2 \mathrm{e} 11$ & 0.3 & \\
\hline
\end{tabular}

Tab. 1 Material properties 
concrete strength is C40, sectional dimension is $500 \mathrm{~mm} \times 500 \mathrm{~mm}$, height is $600 \mathrm{~mm}$,stress mechanism is local eccentric compression, uniformly distributed loading. In order to enhance the veracity, first of all, carry on the research of plain concrete, getting data of ultimate bearing capacity; plain concrete of configurate with conventional steel net .It is steel bar diameter $10 \mathrm{~mm}$,it is a concrete model of $10 \mathrm{~mm}$ with a diameter of $25 \mathrm{~mm}$, number of plies are five, space height between two meshes are $100 \mathrm{~mm}$, according to the GB50010-2010, horizontal and vertical interval is $100 \mathrm{~mm}^{[3]}$; by coolinhg method to achieve the prestressed steel net, it's using $\Phi 7$ rebar, The location of the installation be consistent with plain concrete of configurate with conventional steel net, using pretensioned prestressing to crack resistance of concrete, by cooling method to achieve this in the ABAQUS, displacement and corner of bottom surface all fixed, load increasing linearly, then start to simulate and calculate

\section{Calculation and analysis}

max principal stress in edge local compression $\left(100 \times 500 \mathrm{~mm}^{2}\right)$ as follows:

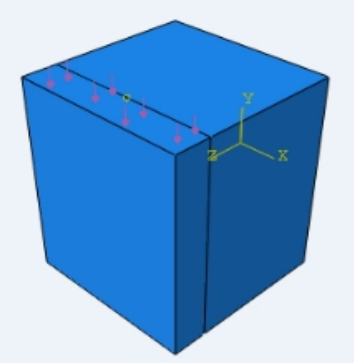

Location of loads
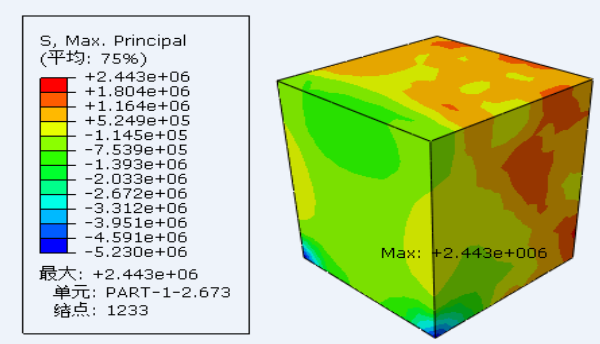

Cloud picture of max principal stress of concrete block
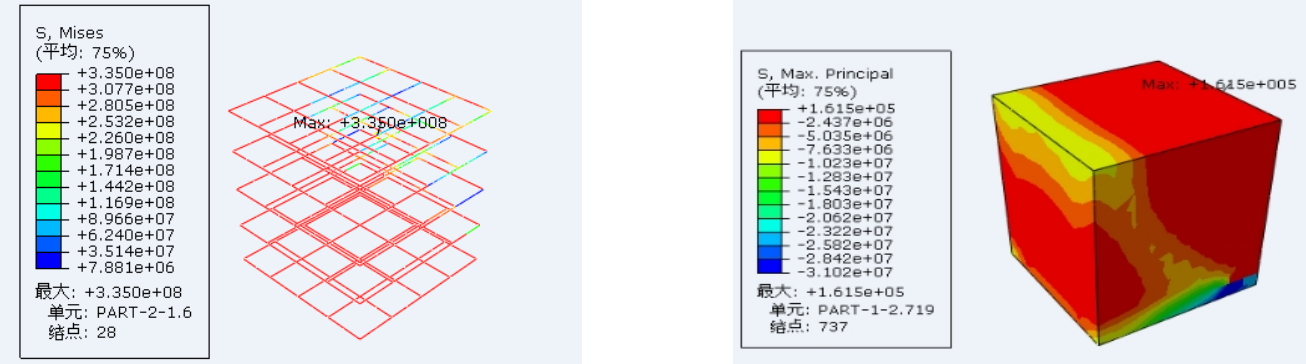

Cloud picture of max principal stress of concrete block and steel net in the plain concrete with conventional steel net
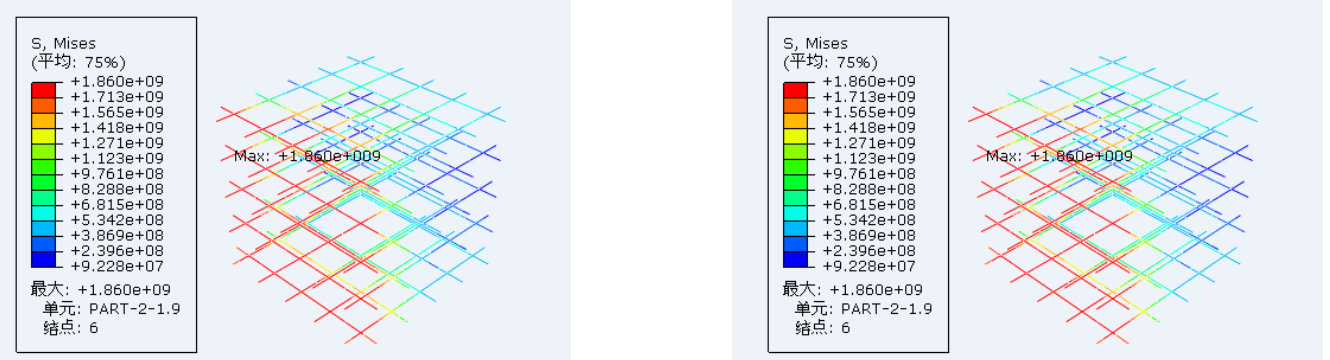

Cloud picture of max principal stress of concrete block and prestressed steel net in the plain concrete with prestressed steel net

Fig. 1. max principal stress

Damage form of plain concrete block is concrete reach the ultimate tensile strength resulting in damage, due to constraint all the bottom, damage location appear in the position close to the bottom; steel bars have yielded clearly in the cloud picture of max principal stress, after reaching the ultimate tensile strength, the concrete tensile deformation; concrete block in the plain concrete with conventional steel net, steel bars yield on the side of local compression, ,intermediate region reach the ultimate tensile strength occur damage in opposite side, concrete near the edge portion of the force does not reach the ultimate compressive bearing capacity. We find that most of the concrete in the block of plain concrete 
did not participate in the work, directly damaged in local part; almost all of the concrete is involved in the work in the block of the plain concrete with conventional steel net; but in the plain concrete with prestressed steel net, prestress make that the stress of most concrete reduced, carrying capacity can be improved significantly.

max principal stress in corner local compression $\left(100 \times 100 \mathrm{~mm}^{2}\right)$ as follows:
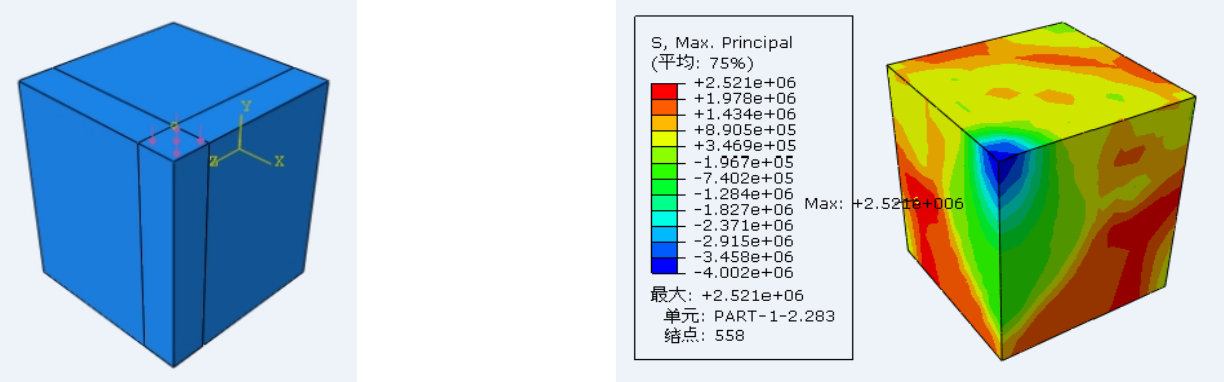

Location of loads

Cloud picture of max principal stress of concrete block
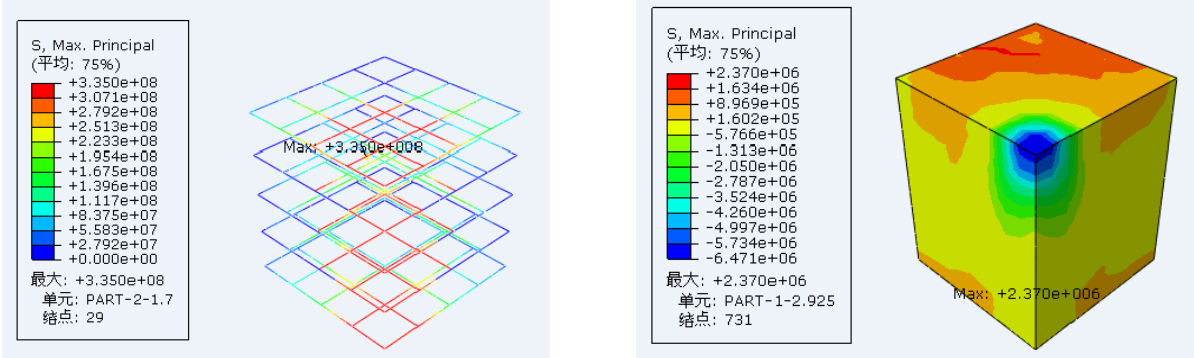

Cloud picture of max principal stress of concrete block and steel net in the plain concrete with conventional steel net
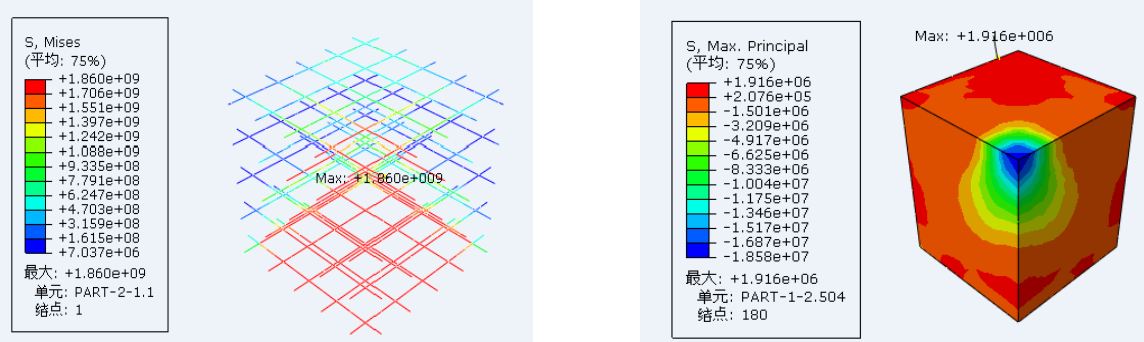

Cloud picture of max principal stress of concrete block and prestressed steel net in the plain concrete with prestressed steel net

Fig. 2. max principal stress

Damage form of concrete block is plain concrete reach the ultimate tensile strength occur destruction. The damage position appears in the middle and lower part of the diagram and is far from the side of the corner; in the cloud picture of max principal stress of steel net in the second block, we can find that steel net have been yielded, after reaching the ultimate tensile strength of concrete, concrete of near the corner portion deforms by pressure; in the third block, the steel bar of the edge have yielded, the yield steel away from the corner of load application increased range, according to the cloud picture of max principal stress of concrete, we can observe that prestressed steel net can improve the integrity of the members. 
max principal stress in corner local compression $\left(200 \times 200 \mathrm{~mm}^{2}\right)$ as follows:

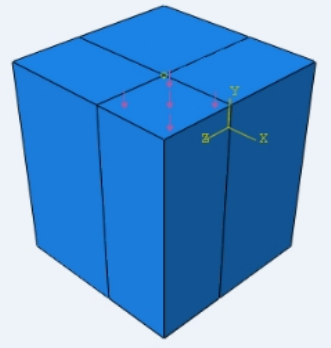

Location of loads

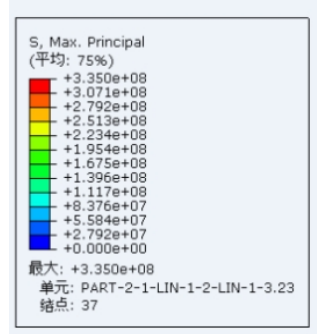

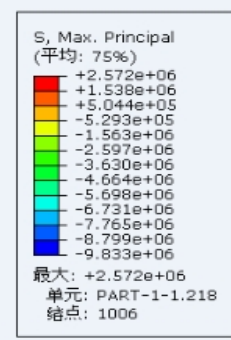

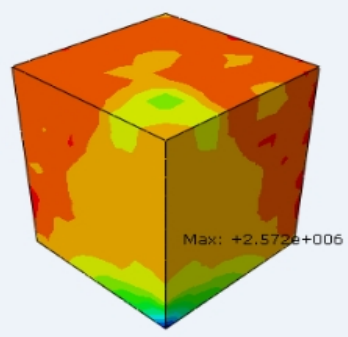

Cloud picture of max principal stress of concrete block
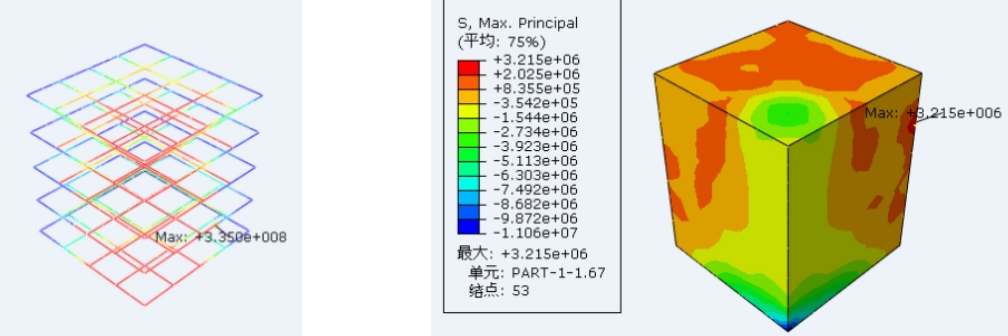

Cloud picture of max principal stress of concrete block and steel net in the plain concrete with conventional steel net
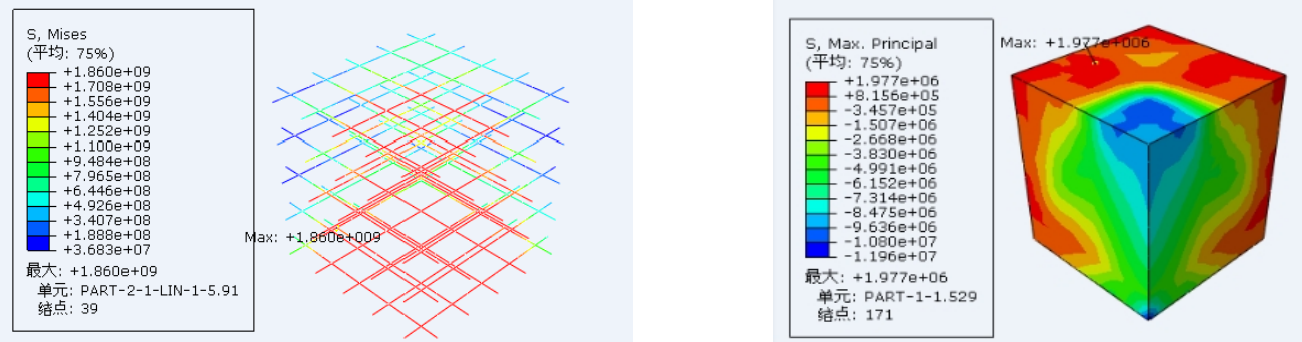

Cloud picture of max principal stress of concrete block and prestressed steel net in the plain concrete with prestressed steel net

Fig. 3. max principal stress

Damage form of concrete block is plain concrete reach the ultimate tensile strength occur brittle failure, the other force form is closed to the block of the corner local compression $\left(100 \times 100 \mathrm{~mm}^{2}\right)$, but improve the working surface of concrete; in the third block, most of the steel bars have been yielded and have certain continuity.

\begin{tabular}{|c|c|c|c|}
\hline & concrete block & $\begin{array}{c}\text { plain concrete with } \\
\text { conventional steel net }\end{array}$ & $\begin{array}{c}\text { plain concrete with } \\
\text { prestressed steel net }\end{array}$ \\
\hline $\begin{array}{c}\text { edge local } \\
\text { compression }\end{array}$ & $96 \mathrm{t}$ & $110 \mathrm{t}$ & $165 \mathrm{t}$ \\
\hline $\begin{array}{c}\text { Corner local } \\
\text { compression } \\
\left(100 \times 100 \mathrm{~mm}^{2}\right)\end{array}$ & $27 \mathrm{t}$ & $38.9 \mathrm{t}$ & $98.4 \mathrm{t}$ \\
\hline $\begin{array}{c}\text { Corner local } \\
\text { compression } \\
\left(200 \times 200 \mathrm{~mm}^{2}\right)\end{array}$ & $117.2 \mathrm{t}$ & $126 \mathrm{t}$ & $252 \mathrm{t}$ \\
\hline
\end{tabular}

Tab .2 Ultimate bearing capacity of the block 


\section{Conclusion}

(1) Brittle failure of plain concrete performs more obvious.

(2) the plain concrete with conventional steel net have a higher carrying capacity.

(3)Implant of prestressed steel net increase in ultimate bearing capacity greater than conventional steel net.

(4) In the partially compressed concrete block, in the area near the local compression part, prestressed steel bar and steel net can take the role of bearing and transferring local pressure.

(5) Implantation of prestressed steel net save the amount of steel, and then play a role in saving material.

(6) With the increase in the area of the corner, the ultimate bearing capacity increases by a small margin. That is when add to the prestressed steel net, the ultimate bearing capacity increases clearly in small local compression area.

\section{Acknowledgements}

The selection of this thesis comes from the National Natural Science Foundation of China. The found ation number is 51178205 .

\section{References}

[1]HU Min-Yun, YANG You-Hua.Experimental study of high strength concrete under local compression [J]. Sichuan Architecture.1996,16(2):52-54.References

[2]CAI Shao-Huai,XUE Li-Hong.Local bearing strength of high-strength concrete [J]. China Civil Engineering Journal, 1994.10:52-61.

[3] CAI Shao-Huai,WEI Shang-Min,JIAO Zhan-Shuan. Bearing strength of confined concrete with transverse net reinforcement [J]. China Civil Engineering Journal, 1986.8:17-24. 